\title{
SELF-REGULATED LEARNING (SRL) MAHASISWA INSTITUT ISLAM MAMBAUL ULUM SURAKARTA DI MASA PANDEMI COVID-19
}

\author{
Fatma Sukmawati \\ Fakultas Tarbiyah, Institut Islam Mamba“ul „Ulum Surakarta \\ fatmasukmawati@dosen.iimsurakarta.ac.id
}

\begin{abstract}
Self-Regulated Learning is important for students, especially when learning is carried out online. This study aims to determine the picture of student self-regulated learning in the lecture process during the pandemic. The online lecture process indirectly makes students adapt to the new learning process. This research method is a quantitative descriptive study with research subjects as many as 70 students of the Islamic Institute of Mamba"ul „Ulum Surakarta (IIM). The results showed that the Self-Regulated Learning of IIM students was in the Very High (ST) category of $10 \%$ or as many as 7 students, for the High Category (T) by $30 \%$ or as many as 21 students, the Medium (S) category was $45 \%$ or as many as 32 students and the Low (R) category is $15 \%$ or as many as 10 students and the Very Low (SR) category is $0 \%$. This shows that there is still need for learning adaptation for students during the pandemic period and there is a need for good Self-Regulated Learning inthemselves.
\end{abstract}

Keywords: Self-Regulated Learning, online learning, pandemic

\section{PENDAHULUAN}

Self-Regulated Learning atau kemandirian belajar merupakan lah satu faktor yang penting dalam mencapai keberhasilan belajar peserta didik. Self-Regulated Learning diperlukan peserta didik supaya mereka mempunyai tanggung jawab, dislipin serta dapat mengembangkan kemampuan belajar atas kemauan sendiri. ${ }^{1}$ Self-Regulated Learning sangat penting dimiliki oleh setiap individu peserta didik baik siswa maupun mahasiswa karena jika tidak direspon secara tepat bisa menimbulkan dampak yang tidak menguntungkan bagi perkembangan psikologis di masa mendatang. Menjadi pribadi yang mandiri merupakan salah satu tugas perkembangan utamanya bagi peserta didik. Peserta didik untuk dapat mandiri membutuhkan kesempatan, dukungan dan dorongan agar dapat mencapai kemandirian atas diri sendiri.

Self-Regulated Learning dapat diartikan sebagai kemampuan individu untuk mengelola secara baik dan efektif pengalaman belajarnya dengan berbagai cara sehingga memperoleh hasil belajar yang optimal. ${ }^{2}$ Self-Regulated Learning dibutuhkan siswa dalam kegiatan belajar agar peserta didik memiliki kemampuan untuk mengatur dan mengarahkan dirinya sendiri, menyesuaikan dan mengendalikan diri, terutama dalam menghadapi tugas yang sulit. Konsep Self-Regulated Learning yang dikemukakan pertama kali oleh Bandura di dalam teori belajar sosial, bahwa setiap individu memiliki kemampuan untuk mengontrol diri tentang cara belajarnya dengan cara mengembangkan langkah-langkah mengobservasi diri, menilai diri,dan memberikan respon bagi dirinya sendiri. ${ }^{3}$ Lebih lanjut menjelaskan bahwa Self-Regulated

\footnotetext{
${ }^{1}$ Tahar, I., \& Enceng. (2006). Hubungan kemandirian belajar dan hasil belajar pada pendidikan jarak jauh. Jurnal Pendidikan Terbuka dan Jarak Jauh, 7(2), 91-101

${ }^{2}$ Wolters., dan Christopher, A. 1998. "Self Regulated Learning and College Students Regulation of Motivation". Journal of Educational Psychology, 90 (2): 224-235.

${ }^{3}$ Irma, A. 2014. "Hubungan Self regulated learning dengan Prokrastinasi Akademik pada Siswa Akselerasi (SMAN 1 Samarinda)". eJournal Psikologi, 2 (2): 227-237.
} 
Learning merupakan proses konstruktif, dimana pebelajar atau peserta didik merancang tujuan belajar dan kemudian berupaya untuk memantau, mengatur dan mengontrol kognisi, motivasi, dan juga perilaku mereka agar sesuai dengan tujuan serta kondisi kontekstual dari lingkungannya.

Self-Regulated Learning adalah self-generation dan self-monitoring terhadap pikiran, perasaan, dan perilakunya agar dapat meraih tujuan. Tujuan tersebut dapat bersifat akademik (meningkatkan pemahaman bacaan, menjadi penulis yang baik, belajar bagaimana mengalihkan, mengajukan pertanyaan yang relevan) atau dapat bersifat sosio-emosional (mengontrol kemarahannya sendiri, berada bersama kawan secara lebih nyaman). ${ }^{4}$ SelfRegulated Learning merupakan proses dimana peserta didik dapat menetapkan tujuan belajarnya dan kemudian berusaha untuk memonitor, mengatur, dan mengontol kognisi, motivasi, dan tingkah lakunya agar sesuai dengan tujuannya dan kondisi kontekstual dari lingkungannya sendiri.

Self-Regulated Learning dapat dilihat dengan adanya kemampuan untuk dapat menyelesaikan masalah yang dihadapi dengan perubahan tingkah laku. ${ }^{5}$ Dengan adanya perubahan tingkah laku, maka kemampuan berpikir peserta didik meningkat, belajar untuk bisa mandiri tanpa mengandalkan bantuan dari orang lain dan mampu bertanggung jawab untuk dapat mengerjakan tugas-tugas rumah tanpa harus melibatkan orang lain. Mereka tidak akan mudah terpengaruh oleh orang lain mengenai proses belajarnya. Mereka juga harus berusaha sebaik mungkin dalam menyelesaikan permasalahannya sendiri tanpa campur tangan atau bantuan orang lain.

Self-Regulated Learning memiliki beberapa karakteristik diantaranya yaitu: (1) peserta didik dapat mendesain belajarnya sendiri sesuai dengan kebutuhan atau tujuan individu yang bersangkutan; (2) peserta didik memilih strategi dan melaksanakan desain belajarnya; dan (3) individu memantau kemajuan belajarnya sendiri, mengevaluasi, hasil belajarnya, serta membandingkan dengan standar tertentu. Selain itu juga, Self-Regulated Learning juga memiliki beberapa indikator yakni: (1) memiliki motivasi belajar intrinsik; (2) memiliki kebiasaan mendiagnosa kebutuhan belajar; (3) mampu menetapkan tujuan/ target belajar; (4) mampu memonitor, mengatur, dan mengontrol belajar; (5) memandang kesulitan sebagai tantangan; (6) mampu memanfaatkan dan mencari sumber yang relevan; (7) mampu memilih dan menerapkan strategi belajar; dan (8) mampu mengevaluasi proses dan hasil belajar. ${ }^{6}$ SelfRegulated Learning sangatlah diperlukan karena salah satu komponen penting dalam mencapai hasil belajar yang baik, selain itu juga sangat diperlukan dalam kondisi saat ini dimana semua peserta didik diharuskan untuk belajar secara mandiri di rumah karena pandemi Covid-19.

Permasalahan yang terjadi saat ini adalah proses pembelajaran yang terpaksa untuk dilakukan di rumah, sejak adanya pandemi Covid-19 yang terjadi di dunia termasuk Indonesia. Di masa pandemi pada saat ini kegiatan pembelajaran harus dapat menyesuaikan keadaan dan kondisi yang terjadi, dimana pembelajaran tidak dapat dilakukan secara tatap muka. Melalui Surat Edaran Nomor 4 Tahun 2020 Tentang Pelaksanaan Kebijakan Pendidikan Dalam Masa

\footnotetext{
${ }^{4}$ Santrock, J.W. 2007. Psikologi Perkembangan. Edisi 11. Jilid I. Jakarta: Erlangga.

${ }^{5}$ Hidayat, dkk. Kemandirian Belajar Peserta Didik Dalam Pembelajaran Daring Pada Masa Pandemi Covid-19. Perspektif Ilmu Pendidikan. Volume 34 Nomor 2. DOI: doi.org/10.21009/PIP.342.9

${ }^{6}$ Handayani, N., \& Hidayat, F. (2018). Hubungan kemandirian terhadap hasil belajar siswa mata pelajaran matematika di kelas X SMK kota cimahi. Journal on Education, 1(2), 1-8.
} 
Darurat Penyebaran Coronavirus Disease (Covid-19), belajar dari rumah melalui pembelajaran daring dilaksanakan untuk memberikan pengalaman belajar yang bermakna bagi peserta didik, tanpa terbebani tuntutan menuntaskan seluruh capaian kurikulum untuk kenaikan kelas maupun kelulusan serta aktivitas dan tugas pembelajaran belajar dari rumah dapat bervariasi antarsiswa, sesuai minat dan kondisi masing-masing, termasuk mempertimbangkan kesenjangan akses/fasilitas belajar di rumah.

Sistem pembelajaran daring menggunakan media jaringan komputer atau gawai dan akses internet. Belajar daring dapat terlaksana dengan baik jika didukung oleh komponenkomponen pembentuknya. Komponen tersebut yaitu: (1) infrastuktur pembelajaran daring, (2) sistem dan aplikasi pembelajaran daring, meliputi sistem perangkat lunak yang digunakan seperti manajemen kelas, materi, forum diskusi, dan sistem penialian; dan (3) konten pembelajaran daring, meliputi bahan ajar berbentuk multimedia atau berbentuk teks. Belajar daring memiliki fokus pandangan yang lebih luas tentang pembelajaran melebihi paradigma pembelajaran tradisional. Belajar daring memiliki fleksibilitas dalam pengolahannya, meskipun terbatas dengan kemampuan dari keberadaan jaringan internet itu sendiri. ${ }^{7}$

Pembelajaran daring dapat menciptakan kemandirian peserta didik dalam belajar seperti mencari informasi mengenai materi kuliah dan tugas yang diberikan kepadanya. Namun kenyataan yang terjadi di lapangan pada saat ini bahwa mahasiswa tidak melakukan SelfRegulated Learning dengan baik. Masih ada mahasiswa yang menunda mengerjakan tugas yang diberikan dosen, membagi waktu dalam mengerjakan pekerjaan rumah dengan tugas dari kampus, sulit membuat rencana dalam mencapai tujuan belajar yang baik, tidak memanfaatkan fasilitas yang ada seperti internet, handphone yang canggih, dan sebagainya. ${ }^{8}$

Hasil penelitian Ade Harahap menunjukkan sebanyak 71,1\% subjek penelitian memiliki Self-Regulated Learning sedang. Hal ini menunjukkan bahwa masih perlu adanya adaptasi belajar bagi mahasiswa selama masa pandemi dan perlu adanya pengaturan diri dalam belajar (Self-Regulated Learning) yang baik pada dirinya.Sehingga peneliti tertarik untuk melihat gambaran dari Self-Regulated Learning mahasiswa pada masa pandemi Covid 19.

\section{METODE}

Penelitian ini merupakan penelitian deskriptif dengan pendekataan kuantitatif. Penelitian deskriptif kuantitatif adalah salah satu jenis penelitian yang bertujuan mendeskripsikan secara sistematis, faktual, dan akurat mengenai fakta dan sifat tertentu, atau mencoba menggambarkan fenomena secara detail. ${ }^{9}$ Penelitian ini dilaksanakan di Institut Islam Mambaul Ulum Surakarta (IIM) tahun akademik 2020/2021 semester genap di bulan Maret 2021. Pemilihan sample penelitian dengan menggunakan teknik Cluster Random sampling. subjek penelitian terdiri dari 70 mahasiswa yang dipilih dalam penelitian ini. Teknik pengumpulan data yang digunakan dalam penelitian ini adalah dengan menggunakan kuesioner dengan skala self-regulated learning untuk mengukur kemandirian belajar peserta didik dan lembar observasi terhadap kegiatan perkuliahan;

\footnotetext{
${ }^{7}$ Aminoto, T., \& Pathoni, H. (2014). Penerapan media e-learning berbasis schoology untuk materi usaha dan energi di kelas XI SMA N 10 kota Jambi. Jurnal sainmatika, 8 (1), 13- 29.

${ }^{8}$ Ade Chita Putri Harahap \& Samsul Rivai Harahap: Covid 19: Self Reguated Learning Mahasiswa. 2010. Jurnal pendidikan konseling. ISSN 2686-2859

${ }^{9}$ Yusuf, A. M. 2014. Metode Penelitian: Kuantitatif, kualitatif, dan penelitian gabungan. Jakarta: Kencana Prenada Media Group.
} 


\section{HASIL DAN PEMBAHASAN}

Dalam penelitian ini, pembelajaran di masa pandemi Covid-19 proses pembelajaran dilaksanakan dengan menerapkan pembelajaran daring menggunakan Google Clasroom. Setiap Dosen dan mahasiswa yang mengikuti perkuliahan harus memiliki akun google. Dengan memiliki akun email google, mahasiswa dapat: (1) membaca materi diunggah oleh dosen pengampu; (2) mengunduh materi atau bahan ajar perkuliahan yang diunggah oleh dosen; (3) mengajukan pertanyaan ataupun mengemukakan pendapat kepada dosen pengampu melalui fitur komentar (comment); (4) mengerjakan tugas, kuis, dan ujian (UTS dan UAS) yang diberikan oleh dosen pengampu; serta e) melihat hasil pekerjaan mereka (tugas, kuis, dan ujian) berupa skor yang mereka capai, berikut umpan balik yang diberikan oleh dosen pengampu.

Dalam penelitian ini, data dikumpulkan dari kuesioner online yang dibagikan secara online kepada mahasiswa di institut islam mambaul ulum surakarta. Data yang didapatkan dalam kuesioner online berjumlah 70 mahasiswa, kemudian data yang sudah diperoleh tersebut dianalisis. Pada pengolahan persentase didapatkan hasil persentase dari frekuensi siswa tiap kategori yaitu sangat tinggi (ST), tinggi (T), sedang (S), rendah (R) dan sangat rendah (SR).

Adapun hasilnya adalah Self-Regulated Learning mahasiwa berada pada kategori Sangat Tinggi (ST) sebesar 10\% atau sebanyak 7 mahasiswa, untuk Kategori Tinggi (T) sebesar $30 \%$ atau sebanyak 21 mahasiswa, kategori Sedang (S) sebesar 45\% atau sebanyak 32 mahasiswa dan kategori Rendah (R) sebesar $15 \%$ atau sebanyak 10 mahasiswa dan kategori Sangat Rendah (SR) sebesar 0\% . Adapun hasil tersebut dapat digambarkan pada grafik berikut:

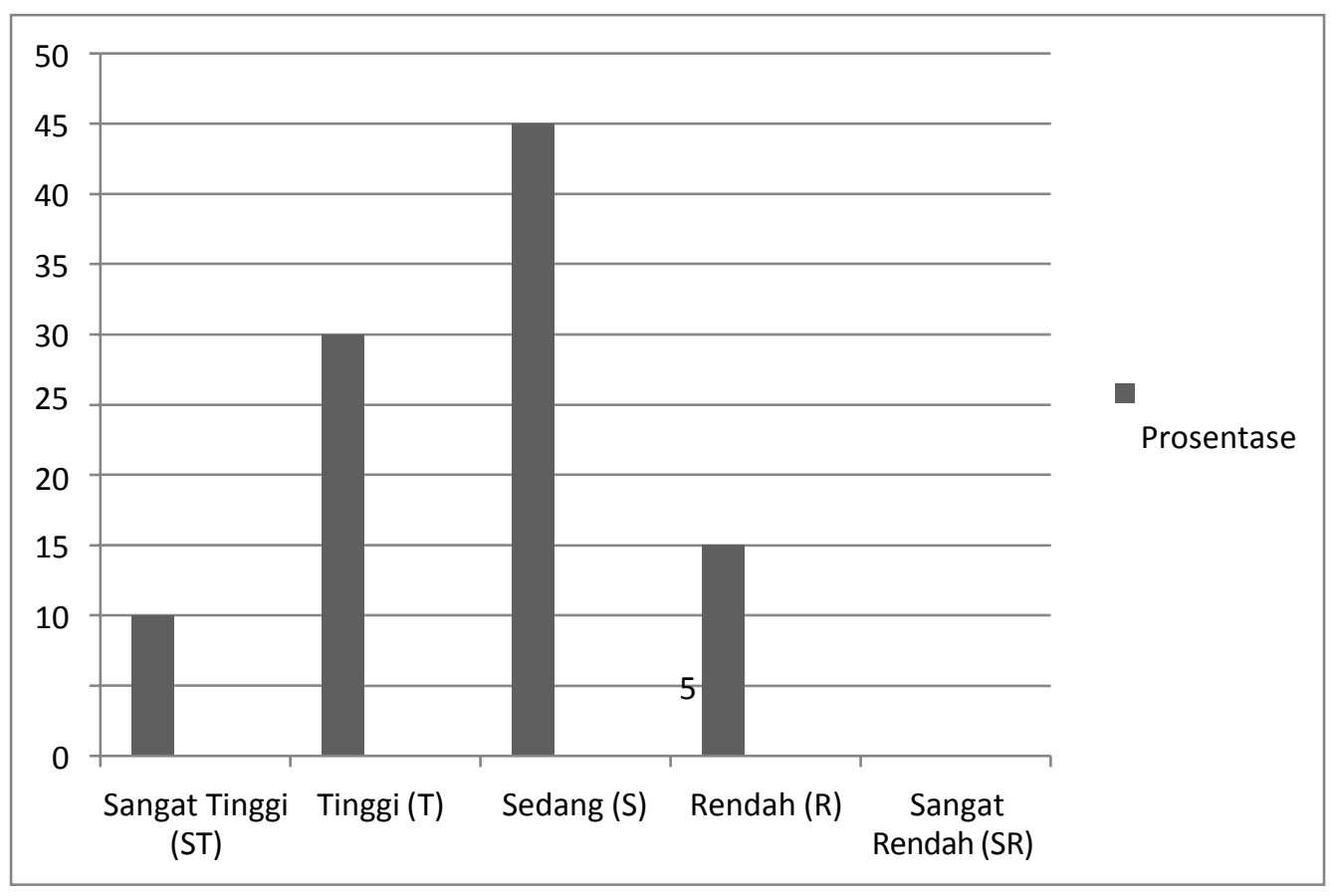

Gambar 1. Persentase self-regulated learning pada mahasiswa IIM Surakarta

Dari hasil temuan yang diperoleh, dapat diartikan bahwa Self-Regulated Learning atau kemandirian belajar mahasiwa paling banyak berada pada kategori sedang yaitu sebesar $45 \%$ dengan jumlah mahasiswa yang memiliki Self-Regulated Learning sedang sebanyak 32. Apabila seseorang memiliki Self-Regulated Learningnya yang baik maka dia berhak untuk 
memberikan penghargaan atas dirinya sendiri dalam pencapaian belajarnya. ${ }^{10}$ Salah satu tanda peserta didik memiliki Self-Regulated Learning yang baik yaitu adanya monitoring terhadap proses-proses kognitif dan afektif yang yang tercakup pada terselesaikannya tugas-tugas akademik dengan baik.

Self-Regulated Learning mahasiswa pada kategori tinggi terdapat 21 mahasiswa. Hal ini berarti bahwa hanya $30 \%$ mahasiswa yang Self-Regulated Learningnya baik. Seorang peserta didik dikatakan memiliki Self-Regulated Learning yang baik dapat dijelaskan dari derajat metakognitif, motivasi dan perilakunya tentang seberapa aktif dirinya dalam proses/kegiatan belajar. Self-Regulated Learning yang baik tergantung pada kepercayaan seseorang terhadap kemampuan mereka dalam mencapai sesuatu yang ditunjukkan dalam sebuah performa. ${ }^{11}$ Artinya bahwa seorang pembelajar mempunyai strategi khusus,memiliki planning (rencana) agar tujuan pembelajaran yang ingin dicapainya dapat diperoleh secara maksimal. $^{12}$

Self-Regulated Learning dapat membantu peserta didik dalam menyelesaikan masalah secara efektif selain membantu peserta didik dalam kesadaran berpikir, penggunaan strategi, dan motivasi yang berkelanjutan. ${ }^{13}$ Self-Regulated Learning yang tertanam pada diri peserta didik akan mempengaruhi kelangsungan perilaku individu itu sendiri. Self regulated merupakan penentu utama berlangsungnya suatu perilaku. ${ }^{14}$ Peserta didik yang berhasil membangun kemandirian belajar yang baik tentu akan memiliki keyakinan dan motivasi yang baik dalam belajar. Dengan ini maka pada akhirnya setiap peserta didik dapat melakukan kewajiban yang ditanggungnya seperti mengerjakan tugas dan mengumpulkan tepat waktu.

Hasil penelitian juga menunjukkan bahwa mahasiswa memiliki tingkat kemandirain belajar yang rendah sebanyak $15 \%$ atau sebanyak 10 mahasiswa. Penyebabnya adalah tidak semua mahasiswa terbiasa belajar melalui daring. Selain itu dosen masih banyak belum mahir mengajar dengan menggunakan teknologi, ini bisa menjadi salah satu alasan rendahnya pembelajaran daring. Para siswa belum memiliki budaya belajar jarak jauh karena selama ini sistem belajar dilaksanakan melalui tatap muka, di Indonesia penggunaan e-learning ini masih termasuk lamban berbeda dengan negara-negara maju diluar yang sudah menggunakan elearning pada tahap yang lebih maju. Daerah-daerah yang tidak memiliki konektivitas jaringan internet yang baik, pembelajaran online menunjukkan kecenderungan yang berbeda, wilayah yang tidak dijangkau jaringan internet seseorang harus menuju area-area tertentu. ${ }^{15}$

Pandemi Covid-19 yang terjadi megharuskan mahasiswa belajar dengan sistem dalam jaringan atau daring. Hal ini memaksa semua pihak yang terlibat dalam proses pembelajaran harus mahir menggunakan teknologi, hal tersebut tentunya membawa perubahan dari

\footnotetext{
${ }^{10}$ Zimmerman. 1990. "Self-Regulated Learning and Achievement: The Emergence of a Social Cognitive Perspective. Educational Psychology Review, 2: 173-201.

${ }^{11}$ Bandura. 1997. Self-Efficacy: The Exercise of Control (New York: W.H. Freeman and Company.

${ }^{12}$ Ade Chita Putri Harahap \& Samsul Rivai Harahap: Covid 19: Self Regulated Learning Mahasiswa. 2010. Jurnal Pendidikan Konseling. ISSN 2686-2859

${ }^{13}$ Sumarmo, U. (2010). Kemandirian belajar: apa, mengapa, dan bagaimana dikembangkan pada peserta didik.http://math.sps.upi.edu/wp-content/uploads/2010/02/KEMANDIRIAN-BELAJAR-MAT-Des-06-new.pdf. Diakses 4 mei 2021

${ }^{14}$ Utami, Sri, Anna Rufaidah dan Afiatin Nisa.2020.’Kontribusi Self-Regulated Learning terhadap Stress Akademik Mahasiswa Selama Pandemi Covid -19 periode April-Mei 2020”.Universitas Indraprasta PGRI

${ }^{15}$ Firman, \& Rahman, S. R. (2020). Pembelajaran Online di Tengah Pandemi Covid-19. Indonesian Journal of Educational Science (IJES), 2(2), 81-89. DOI: 10.31605/ijes.v2i2.659
} 
pembelajaran tatap muka biasanya. Dalam pembelajaran tatap muka, interaksi sosial bisa tetap terjadi di dalam kelas di mana peserta didik memang masih perlu panduan dalam pembelajaran. Melalui pembelajaran tatap muka, peserta didik bisa berinteraksi dengan pendidik maupun teman mereka sehingga peserta didik akan secara langsung memperoleh feedback dari hasil pembelajaran. ${ }^{16}$

Pembelajaran daring memiliki sisi positif yaitu berkembangnya Self-Regulated Learning peserta didik. Melalui pembelajaran daring, mahasiswa dapat dengan bebas mengatur strategi belajarnya sendiri. Mahasiswa tidak terikat oleh waktu dalam pembelajaran daring, karena mereka dapat mengatur sendiri jadwal dan tempat dimana mereka ingin mengikuti perkuliahan. pembelajaran daring memungkinkan akses informasi dan pengetahuan di rumah dan di manapun yang disesuaikan dengan kenyamanan peserta didik. Selain itu pembelajaran secara online menghilangkan perasaan canggung sehingga dapat mengekpresikan fikirannya dan bertanya secara bebas. ${ }^{17}$

\section{KESIMPULAN}

Dari hasil penelitian yang diperoleh Self-Regulated Learning mahasiswa institut islam mambaul ulum Surakarta berada pada kategori sedang. Penelitian ini menunjukkan bahwa mahasiswa masih cukup memiliki kepercayaan diri dan tanggung jawab untuk belajar secara daring. Mahasiswa harus memiliki kesiapan dan disiplin diri (self-discipline) dalam melaksanakan pembelajaran daring agar terbiasa dengan perubahan yang ada. Berbagai manfaat dan hasil yang diperoleh jika mahasiswa melakukan Self-Regulated Learning dalam kegiatan belajarnya baik itu kegiatan belajar secara langsung maupun kegiatan belajar secara daring yaitu tujuan belajar dapat tercapai dengan baik dan maksimal.

\section{DAFTAR PUSTAKA}

Ade Chita Putri Harahap \& Samsul Rivai Harahap: Covid 19: Self Reguated Learning Mahasiswa. 2010. Jurnal Pendidikan Konseling. ISSN 2686-2859

Ade Chita Putri Harahap \& Samsul Rivai Harahap: Covid 19: Self Reguated Learning Mahasiswa. 2010. Jurnal Pendidikan Konseling. ISSN 2686-2859

Aminoto, T., \& Pathoni, H. (2014). Penerapan Media e-Learning Berbasis Schoology untuk Materi Usaha dan Energi di Kelas XI SMA N 10 Kota Jambi. Jurnal Sainmatika, 8 (1), 13- 29.

Anhusadar, L. O. (2020). Persepsi Mahasiswa PIAUD terhadap Kuliah Online di Masa Pandemi. KINDERGARTEN: Journal of Islamic Early Childhood Education, 3 (1), 4458. DOI: $10.24014 /$ kjiece.v3i1.9609

Bandura. 1997. Self-Efficacy: The Exercise of Control (New York: W.H. Freeman and Company.

\footnotetext{
${ }^{16}$ Anhusadar, L. O. (2020). Persepsi Mahasiswa PIAUD terhadap Kuliah Online di Masa Pandemi. KINDERGARTEN: Journal of Islamic Early Childhood Education, 3 (1), 44-58. DOI: 10.24014/ kjiece.v3i1.9609

${ }^{17}$ Herliandry, L. D., Nurhasanah, Suban, M. E., \& Kuswanto, H. (2020). Pembelajaran Pada Masa Pandemi Covid-19. Jurnal Teknologi Pendidikan, 22(1), 65-70. DOI: 10.21009/jtp.v22i1.15286
} 
Firman, \& Rahman, S. R. (2020). Pembelajaran Online di Tengah Pandemi Covid-19. Indonesian Journal of Educational Science (IJES), 2(2), 81-89. DOI: 10.31605/ijes.v2i2.659

Handayani, N., \& Hidayat, F. (2018). Hubungan Kemandirian terhadap Hasil Belajar Siswa Mata Pelajaran Matematika di Kelas X SMK Kota Cimahi. Journal on Education, $1(2), 1-8$.

Herliandry, L. D., Nurhasanah, Suban, M. E., \& Kuswanto, H. (2020). Pembelajaran Pada Masa Pandemi Covid-19. Jurnal Teknologi Pendidikan, 22(1), 65-70. DOI: 10.21009/jtp.v22i1.15286

Hidayat, dkk. Kemandirian Belajar Peserta Didik Dalam Pembelajaran Daring Pada Masa Pandemi Covid-19. Perspektif Ilmu Pendidikan. Volume 34 Nomor 2. DOI: doi.org/10.21009/PIP.342.9

Irma, A. 2014. "Hubungan Self-Regulated Learning dengan Prokrastinasi Akademik pada Siswa Akselerasi (SMAN 1 Samarinda)". e-Journal Psikologi, 2 (2): 227-237.

Santrock, J.W. 2007. Psikologi Perkembangan. Edisi 11. Jilid I. Jakarta: Erlangga

Sumarmo, U. (2010). Kemandirian belajar: apa, mengapa, dan bagaimana dikembangkan pada peserta didik. http://math.sps.upi.edu/wp-content/uploads/2010/02/KemandirianBelajar-Mat-Des-06-New.Pdf. Diakses 4 Mei 2021

Tahar, I., \& Enceng. (2006). Hubungan kemandirian belajar dan hasil belajar pada pendidikan jarak jauh. Jurnal Pendidikan Terbuka dan Jarak Jauh, 7(2), 91-101

Utami, Sri, Anna Rufaidah dan Afiatin Nisa.2020."Kontribusi Self-Regulated Learning Terhadap Stress Akademik Mahasiswa Selama Pandemi Covid -19 periode April-Mei 2020”.'Universitas Indraprasta PGRI

Wolters., dan Christopher, A. 1998. "Self-Regulated Learning and College Students Regulation of Motivation”. Journal of Educational Psychology, 90 (2): 224-235.

Yusuf, A. M. 2014. Metode Penelitian: Kuantitatif, Kualitatif, dan Penelitian Gabungan. Jakarta: Kencana Prenada Media Group.

Zimmerman. 1990. "Self-regulated learning and Achievement: The Emergence of a Social Cognitive Perspective. Educational Psychology Review, 2: 173-201. 